\title{
Study on the Application of CLIL in English Teaching of Acupuncture and Moxibustion
}

\author{
Cheng Liu, Xiaofang Wang \\ School of Humanities, Jiangxi University of Traditional Chinese Medicine, Nanchang, 330004, China \\ jxjzlc@163.com
}

\begin{abstract}
CLIL ( Content Language Integrated Learning ) is the organic combination of language skills and the specific content of knowledge. Through the use of the CLIL method in high grades English teaching, this paper proves that CLIL can improve learners' oral English proficiency in English teaching in high grades of university. And in this case, students' interest will be aroused in learning English and some problems of English teaching can be solved in colleges. All these can provide new views for the reform of current English teaching.
\end{abstract}

Index Terms - CLIL, Professional English Teaching, Acupuncture and moxibustion

\section{The Connotation of CLIL}

CLIL is short for Content and Language Integrated Learning, which is a term created in 1994 by David Marsh and Anne Maljers as an approach for learning content through a foreign or second language. CLIL insists that students in the classroom use the target language as a tool to explore knowledge, and promote the development of target language. This kind of teaching idea is considered as a natural way of developing language ability, and it is consistent with the approach of the initial learning of our mother tongue.

The teaching idea of CLIL is popularized with different extent in European countries in language teaching. This idea of combining language learning and content learning has been gradually accepted and applied to the education of every country with different degrees. It is described as "the best method of making progress in learning a foreign language" by the European Commission. The teaching method has a corresponding change, forming two main teaching modes of blending language and content: one is immersion method, which means completely immersing in a language and learning related content, learning content of different subjects by non-native language, and also mastering the professional field of language communication skills. In this way, the professional skills and language features progress together. Immersion method which starts from the French teaching in Canada spreads to the rest of the world and has different patterns of "immersion method". The other is the thematic teaching which combines the non native language with specially designed subject content to conduct teaching in the form of special topics. It is more than a step forward compared with the immersion method. It re-integrates the subject content by means of the second language. This method is obviously better in cultivating the students' non-native thinking ability and its reform is greater.

\section{The Theoretic basis of CLIL}

The theoretic basis of CLIL is a new teaching theory deriving from the "communicative competence" of Hymes and Halliday's "functional linguistics". It develops and forms based on the further acquaintance with language function and communicative purpose. CLIL is teaching or learning courses of non-language subjects through using the second (third/fourth) language. And it is also a strategy for subject research. Therefore, it is different from foreign language teaching. The reason is that during the process of CLIL teaching foreign language is just a tool of learning or teaching other subjects. In other words, although language and subject learning are all the main purposes of CLIL, educators and learners should pay more attention to the topics instead of language in using CLIL teaching method. Broadly speaking, the goal of CLIL is to enhance learners' professional knowledge and skills, at the same time learners' language competence is enhanced for the language is used in the curriculum teaching. The language becomes the media of learning professional knowledge, and the professional knowledge provides context and resources for language learning. According to professor Coyle's 4Cs Framework in the University of Nottingham, the teaching purposes of CLIL can be summarized with four words: Communication, Content, Culture, and Cognition. These four words fully embodies that CLIL Teaching is oriented by content and culture, regarding language as a medium, emphasizing the communication between the teacher and the learner, and the communication among scholars. All these can improve the cognitive ability of scholars' professional content or cultural knowledge.

\section{The Study on CLIL Application}

This research employs CLIL teaching method in English courses. Taking into account the students' major, the study selects acupuncture and moxibustion which is their familiar course. The teacher designs classroom activities or tasks through the course content. The teacher not only emphasizes learning subject content, but also pays attention to regulating students' English language using, reaching the interactions between language and the teaching content, students' interactions with the language environment, and the interactions between teachers and students. We must ensure the interactions between any two of the four aspects: communication, content, culture, and cognition. 


\subsection{Research Object}

The object of this study is 80 sophomores from class of acupuncture and rehabilitation and class of acupuncture and massage, Clinical Medical College of Jiangxi University of Traditional Chinese Medicine. Class of acupuncture and rehabilitation is selected as the experimental class, and class of acupuncture and massage is the control class. These two classes have the same class periods and the same teacher. Previous data analysis showed that the two classes have similar oral English level (Table I).

\subsection{The Purpose of the Study}

Through the experimental comparison, it was to study the effect of CLIL teaching method in improving the students' oral English ability and its advantages.

\subsection{Research Time}

The study lasted one semester, 3 hours in a week, and 42 hours in all.

\subsection{The Research Process}

CLIL teaching model was used in the experimental group, adapting Acupuncture and Moxibustion (English Version) as the text book and some teacher-made materials. The control group employed traditional teaching methods, using College English (Book Four) as the text book to learn general English course. The research tool was a questionnaire and the IELTS speaking test. The software of SPSS 17.0 was used to analyze the experimental results and statistical analysis, and the research data are listed as follows:

TABLE I (pre-test)

\begin{tabular}{|c|c|c|c|c|}
\hline & Class & Number & Mean & Standard deviation \\
\hline \multirow{2}{*}{ Score } & Experimental group & 40 & 50.34 & 4.071 \\
\cline { 2 - 5 } & Control group & 40 & 50.67 & 4.102 \\
\hline
\end{tabular}

TABLE II (post-test)

\begin{tabular}{|c|c|c|c|c|}
\hline & Class & Number & Mean & Standard deviation \\
\hline \multirow{3}{*}{ Score } & Experimental group & 40 & 60.01 & 4.825 \\
\cline { 2 - 5 } & Control group & 40 & 53.78 & 4.304 \\
\hline
\end{tabular}

TABLE III T-test of the scores in the two groups

\begin{tabular}{|c|c|c|c|}
\hline & & Pre-test & Post-test \\
\hline \multirow{3}{*}{ Score } & $\mathrm{t}$ & 1.012 & 0.729 \\
\cline { 2 - 4 } & Sig. & 0.489 & 0.001 \\
\hline
\end{tabular}

Through table 1, we can find that the mean score in control group is slightly higher than that in the experimental group in pre-test, and achievements in the two groups have little difference; however, table 2 shows that the average score of the experimental group increases significantly faster than that in the control group. The mean of experimental group is 60.01 , and the mean of control group is 53.78. Table 3 shows that there is no significant difference between the mean value of the two groups in pre-test $(\mathrm{P}=0.489)$, which indicates that the oral English level of students in the two groups is of the same level. However, after a semester's experiment, there is significant difference between the two groups $(\mathrm{P}=0.001)$, indicating that in the experimental group students' English speaking ability improved greatly after using the CLIL teaching method. In the pretest, there is no big difference in aspects of oral expression, vocabulary and grammar, sentence structure and so on between the experimental group and the control group, but in the post-tests, significant differences exist between the two groups in these areas (the $\mathrm{P}$ value is 0.001). Compared with the control group, the oral expression ability in the experimental group is higher, more accurate in wording, and more fluent in language using.

The experimental data show that CLIL teaching method has significant effect in improving the students' oral English level. Compared with traditional teaching methods, the teaching mode of CLIL blends subject knowledge with language, making the scene of language utilization more concrete and real. This teaching mode stimulates the students' motivation to learn the language, deepens their understanding of the subject knowledge, and enhances the cross-cultural awareness and ability. Students' cognitive level is improved significantly, and so is the ability of spoken language.

\subsection{Discussion}

Through this research, we can sum up the following experience. Firstly, university English teaching should focus on the content of teaching, and enhance students' English learning motivation. Students get to acquire English knowledge through learning the subject content knowledge in a very natural way. Teachers should strengthen students' English input and stimulate their interest in learning English by guiding the students to use English as a tool to learn the scientific or social knowledge, to broaden their horizons, to improve the knowledge structure. It is an efficient way to improve the students' ability of using English, especially the oral expression ability. Secondly, teachers should strengthen the interactions between teachers and students, and pay attention to the classroom communication. Teachers should also reasonably design tasks, and increase opportunities of students' output. The classroom should be centered on students. We can make use of the specific subject content to provide real communication environment close to their majors, encouraging students to carry out exchanges and cooperation, promoting the students' language output, increasing practical exchange opportunities of applying English for specific subject content, and improving the efficiency of English learning. Thirdly, teachers should not consider the College English Test Band-4 or 6 as the ultimate goal in the process of teaching, but should regard the learners' fluent using of English as the purpose. Teachers should design various kinds of activities for students to join in and dilute the learning objectives of vocabulary and grammar and so on. So that the students' English learning will become an effective mean to learn professional knowledge. Teachers create good and relaxed English learning environment for students, making them understand that language fluency is more important than 
accuracy and errors are unavoidable part of learning language. Finally, teachers should establish a full-sided teaching evaluation system and consider the formative assessment in the process of students' learning comprehensively. Teachers cannot make the final exam as the only evaluation criteria, and they should evaluate students from the classroom performance, the aspects of spoken English and the specific content as well.

\section{Conclusion}

CLIL teaching mode regards the teaching contents as its goal, and puts emphasis on cultivating students' ability of culture, communication and cognition, making English language become the carrier of content. The use of CLIL teaching method in high grades of university can stimulate students' interest in learning English. At the same time, through the reasonable task, it artfully links the contents with English language skills. Students can use English to express and evaluate professional knowledge, and enhance students' ability of communicating with others, expressing their ideas, and discussing academically in English. It can gradually help students to turn from the knowledge, skills, and examination oriented English learning to the ability of Applied English learning. Ultimately, it will improve the effect of college English teaching. Therefore, CLIL teaching provides a direction for college English teaching reform in China.

\section{References}

[1] Coyle, D. Content and Language Integrated Learning//Encyclopedia for Language. Learning Volume 4. Berlin: Springer-Verlag, 2007.

[2] Coyle, D., Hood, P. \& Marsh, D. Content and Language Integrated Learning. Cambridge: CUP, 2010, 1.

[3] Dalton- Puffer, C. Discourse in Content and Language Integrated Learning (CLIL) Classrooms. Amsterdam: John Benjamins Publishing Company, 2007.

[4] Guo Yueqin, Wu Xiujuan. On the Application of CLIL in College English Writing. Foreign Language and Literature, 2013(4): 166-169.

[5] Liu Yaling, Chen Yueting. On CLIL and It's Inspiration for EFL Teaching Reform. Overseas English, 2011(11): 56-58. 